\title{
EDUCATION
}

\section{Senior house officer training in oral and maxillofacial surgery: a national survey}

\author{
D. J. W. Keith ${ }^{1}$ and J. Durham ${ }^{2}$
}

The aim of the present study

was to see

whether and

how training

for Senior

House Officers

in Oral and

Maxillofacial

Surgery had changed since the last published survey in 1995

\footnotetext{
${ }^{1}$ Specialist Registrar in Oral and Maxillofacial Surgery, ${ }^{2}$ Senior House Officer in Oral and Maxillofacial Surgery, Oral
Oracial Surgery, 2 Senior House Officer in Oral and Maxillofacial Surgery, Oral Hospital, Kayll Road, Sunderland, UK Correspondence to: David J W Keith, 1 Barnard Court, Woodstone Village, Houghton Le Spring, Tyne \&t Wear DH4 6TS, UK

E-mail:djwkeith@tinyworld.co.uk
}

Summary Service commitments have often taken priority over training for many senior house officers. There have been changes, with more planned to make this truly a training grade. We conducted a national postal survey of senior house officers (SHO) in oral and maxillofacial surgery (OMFS) in 2001/2002. A total of 229 replies were received with an estimated response rate around 70\%. Almost 60\% of these respondents (57.2\%) had been a SHO in OMFS for over 3 years. Only 39\% had a weekly bleep-free teaching session. Forty-eight per cent did not think undergraduate BDS training was adequate for their job. This $48 \%$ of SHOs were significantly less likely to have out patient clinic sessions with a designated trainer undertaking teaching $\left(\chi^{2}=6.127, P=0.013\right)$ or have a bleep-free teaching session $\left(\chi^{2}=6.896, P=0.009\right)$. Sixty-four per cent had received formal training in medical examination of patients. Twentynine per cent had not been appraised during their present post. Forty-two per cent of SHOs in OMFS are in band 3 posts. Improvements have been made, but there is a case for further change.

\section{INTRODUCTION}

The consultation document on the review of workforce planning, 'A Health Service of all the talents: Developing the NHS workforce'1 grasps the predicament of many senior house officers (SHOs). The Department of Health stated, in April 2000: 'The SHO grade is widely seen as a problem area, with trainees providing an undue service commitment and large numbers of staff in a training grade who are not in reality in training at all.'

The past 10 years have seen many letters and publications going over the same issue of too much service commitment and not enough training. There has been inadequate supervision and teaching, with increasing clinical work. ${ }^{2-6}$

Lyons and Mills ${ }^{7}$ surveyed 145 SHOs in Oral \& Maxillofacial Surgery (OMFS) in 1995. They also found deficiencies in teaching and the level of supervision given. Since then there have been many changes, all hoping to improve the working conditions and training of the junior doctor. Specialist registrar training replaced the old registrar/senior registrar pathway after recommendations in 1992 by Kenneth Calman, Chief Medical Officer. ${ }^{8}$ These changes were finally completed in 1997. 'The new deal' led the way in reducing doctor's hours, with changes in on-call arrangements. ${ }^{9}$ From 1994, SHO posts increased to allow the promised reduction in hours of work. ${ }^{10}$ Paice et al. ${ }^{11}$ showed a greater satisfaction among trainees of all grades with their post after the reforms of specialist training. This was despite concerns that the reforms may have an adverse affect on more junior grades of training.

Attempts have been made to address the concerns with the senior house officer post. 'The Early Years recommendations on Senior House Officer Training' by the General Medical Council emphasises the need for appropriate education and supervision, with sub-standard posts being terminated. The importance of induction programmes and appraisal was emphasised with delegation of responsibility for ensuring standards are met. ${ }^{12}$

With the recent publication of the Chief Medical Officer's (CMO) proposals. Sir Liam Donaldson has 


\section{Table 1}

Number of years that Senior House Officers have been qualified from dental school

\begin{tabular}{|l|c|c|}
\hline Years qualified & No. of SHOs & Percentage (\%) \\
\hline $1-2$ & 62 & 27.5 \\
$3-4$ & 69 & 30.7 \\
$5-6$ & 52 & 23.1 \\
$7-8$ & 19 & 8.5 \\
$9-10$ & 15 & 6.6 \\
$>11$ & 8 & 3.4 \\
\hline
\end{tabular}

\section{Table 2}

Dental school where each SHO qualified

\begin{tabular}{|l|c|c|}
\hline Dental school qualified & No. of SHOs & Percentage (\%) \\
\hline England & 91 & 41.9 \\
Wales & 15 & 6.9 \\
Scotland & 28 & 12.9 \\
Northern Ireland & 1 & 0.5 \\
Europe & 4 & 1.8 \\
Asia & 53 & 24.4 \\
Africa & 8 & 3.7 \\
Other & 17 & 7.8 \\
\hline
\end{tabular}

suggested 19 proposals for the reform of the SHO grade in 'Unfinished Business', August 2002. ${ }^{13}$ SHO posts are likely to become more programme-based, time-capped, with introduction of the Record of In Training Assessment (RITA) process. It is suggested that development of a 'run-through training grade in which doctors move seamlessly through training with satisfactory progress checks' should be explored.

SHOs in oral and maxillofacial surgery occupy a unique place in the debate. Most, if not all, are dentally qualified and very few are medically qualified. The vast majority of posts are not part of a rotation through other specialties. The pathway to specialist registrar training, if taken, will lead such SHOs through medical school, pre-registration posts, and further SHO training. The responsibility of matching SHO posts in dentistry to the recommendations in 'Unfinished Business' is the task of the Chief Dental Officer (CD0). It is not clear what the effect of such planned changes will have on training in OMFS.

Expected standards for SHO training in oral and maxillofacial surgery posts were published in 2002 by The Conference of Postgraduate Dental Deans and Directors and The Faculty of Dental Surgery, Royal College of Surgeons, England. ${ }^{14}$ It is expected that all SHOs have a named educational supervisor, have an induction programme, participate in audit sessions, have scheduled appraisal, and a structured training programme. Specific requirements of a SHO post in oral and maxillofacial surgery should include an average of one session per week of the following: outpatients with a designated trainer undertaking teaching - minor oral sur- gery and operating under general anaesthetic in theatre with a designated trainer undertaking teaching; one bleep-free teaching session with an organised training curriculum; and one session of ward work. No more than one session of either preadmission clinic, clerking on the ward, unsupervised minor oral surgery, or unsupervised outpatient clinics are recommended.

The aim of the present study was to examine via a postal survey of SHOs in OMFS training whether, and how, this training has changed since the last published survey in $1995 .^{7}$ The survey would also reveal if and how the SHO training falls short of recommended standards in the UK.

\section{METHOD}

A 28 item ad hoc questionnaire was compiled and designed to elicit responses either from Likert scales or simply choosing yes/no. The questionnaire evaluated such topics as qualifications, opinions about training, weekly timetable and on-call commitments. Confidence in their job was assessed by asking about how often they felt out of depth, overwhelmed or lacking in confidence with patient management. This ranged from always feeling out of depth, with a score of 0 , to never feeling out of depth with a score of 5 . The anonymous questionnaires were posted, with a covering letter, to Oral \& Maxillofacial Units in the United Kingdom. SHO posts and units were identified from the list of recognised posts held by the Royal Colleges and the Unit Directory from the British Association of Oral \&t Maxillofacial Surgery. SHOs were asked to only complete the questionnaire if they had a permanent post. This was intended to avoid locums and clinical assistants returning the questionnaires and giving an unfair reflection of training. We estimated there were 300 to 350 SHO in oral and maxillofacial surgery in the United Kingdom. Questionnaires were posted throughout November 2001. Reminders were sent in January 2002. The returned questionnaires were entered into a database and analysed with SPSS (Version 10).

\section{RESULTS}

A total of 229 questionnaires were returned with a response rate of around $65-76 \%$. The group consisted of $48.2 \%$ male and $51.8 \%$ female.

\section{Career progression}

On average the SHOs were 4.2 years post qualification (Table 1) and worked as SHOs in OMFS for 1.5 years on average, but this ranged from 1 to 7 years. Overall, $41.8 \%$ had been qualified for over 4 years, and $57.2 \%$ had worked as a SHO in OMFS for over 3 years.

The majority, 62.2\%, had qualified from dental schools in the United Kingdom (Table 2). Considering the $37.8 \%$ of SHOs who qualified overseas revealed some significant differences when compared with UK graduates. SHOs who qualified overseas were more likely to be male $\left(70.7 \%\right.$ male; Pearson $\chi^{2}=$ 25.934, $P<0.001$ ), compared with UK qualified 
SHOs (35.6\% male). In addition, non-UK graduates had been qualified for longer (Mann-Whitney UTest, $Z=-10.092, P<0.001)$, and worked as a SHO in OMFS for longer (Mann-Whitney $U$ Test, $z=-7.543$, $P<0.001)$. Of non-UK graduates $97.5 \%$ had been a SHO in OMFS for over 3 years, compared with 31.9\% of UK graduates.

\section{Postgraduate qualifications}

Most SHOs (70\%) had additional postgraduate qualifications, (including Part A MFDS, and 39\% had completed FDS or MFDS (Table 3). Non-UK graduates were better qualified with 58.5\% having FDS or MFDS, compared with $28.1 \%$ of UK graduates (Pearson $\chi^{2}=21.910, P<0.001$ ).

\section{Training experience}

When asked about their exposure to different aspects of training $82 \%$ felt their exposure to cleft lip and palate treatment was deficient. Almost a third also felt exposure to oncology and orthognathic surgery was deficient (Fig. 1).

\section{Weekly timetable}

The average SHO has a week consisting of 3.7 operating sessions (LA and GA), 3.2 outpatient clinic sessions, and 1.8 ward work sessions. Most senior house officers (71\%) have a weekly study session. But $87 \%$ may have to sacrifice this session because of work commitments with a third having to do this more than $50 \%$ of the time. Only 39\% have a bleep-free weekly teaching session, and 38\% have a weekly session for administration or audit tasks.

\section{Supervision}

Operating sessions can be as the most senior operator for general anaesthetic cases in 30\% of respondents, and $47 \%$ have regular local anaesthetic minor oral surgery sessions with a designated trainer. Out-patient clinics are also with a designated trainer undertaking teaching for $61 \%$ of SHOs.

\section{Undergraduate training}

Opinions were split concerning how adequate their undergraduate BDS training was for their post, with $48 \%$ of the opinion that it was not adequate. Having the opinion that BDS training was inadequate

\section{Table 3}

Qualifications of Senior House Officers in survey

\begin{tabular}{|l|c|c|}
\hline Qualifications & No. of SHOS & Percentage of total (\%) \\
\hline BDS & 229 & 100 \\
MBChB & 5 & 2.2 \\
FDS part 1 & 4 & 1.7 \\
FDS/FFD & 50 & 21.8 \\
MFDS part A & 58 & 25.3 \\
MFDS part B & 14 & 6.1 \\
MFDS & 39 & 17 \\
MDS & 21 & 9.2 \\
BSC / BMsc & 17 & 7.4 \\
FRCS & 2 & 0.9 \\
Other & 9 & 3.9 \\
\hline
\end{tabular}

Percentage of SHOs
Fig. 1 Opinions of Senior House Officers about exposure to maxillofacial surgery aspects of oral $\mathbb{C t}$

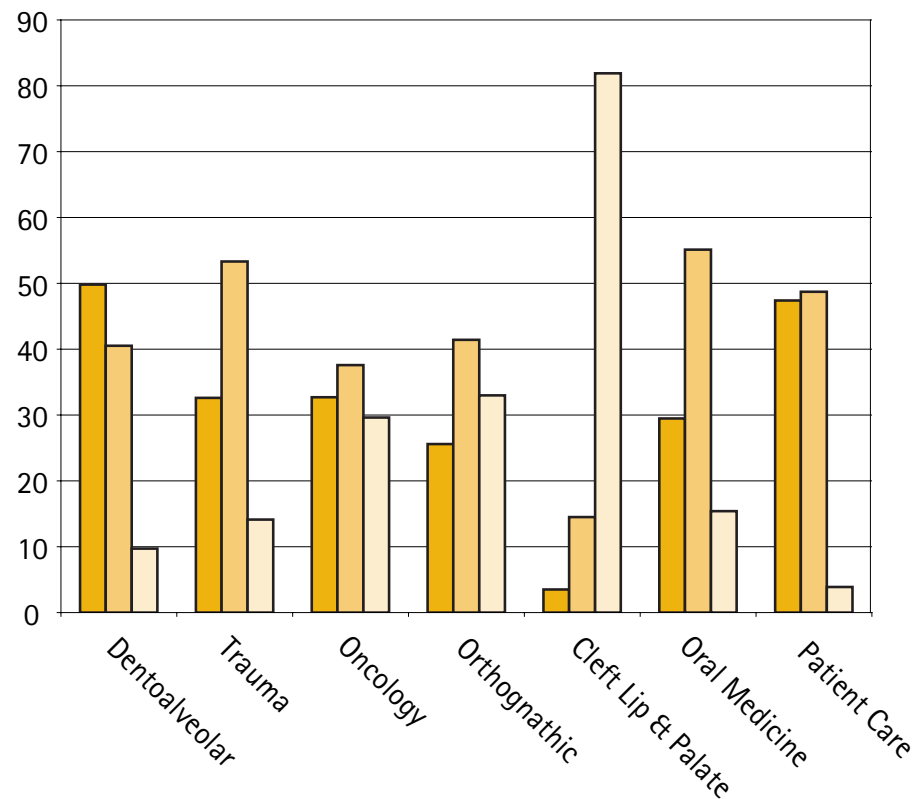

was significantly associated with less time qualified from dental school, (Mann Whitney $U$ Test, $\mathrm{z}=-3.179, P=0.001)$ and less time as a senior house officer (Mann Whitney $U$ Test, $z=-2.9$, $P=0.003)$. In addition, those who felt their BDS training inadequate were significantly less likely to have out-patient clinic sessions with a designated trainer undertaking teaching (Pearson $\chi^{2}=6.127$, $P=0.013$ ), or have a bleep-free teaching session (Pearson $\chi^{2}=6.896, P=0.009$ ). Correspondingly, there was a significant association between greater frequency of feeling out of depth in their job and thinking that BDS training was inadequate (Mann Whitney $U$ Test, $z=-3.774, P<0.001)$.

\section{Confidence at work}

We explored confidence at work by asking how often they felt out of their depth, overwhelmed or lacking in confidence with patient management. Not surprisingly, the longer qualified from dental school (Spearmans Rho, correlation coefficient $=0.432, P<0.001$ ) or the more time as a SHO (Spearmans Rho, correlation coefficient $=0.418, P<0.001)$ positively correlated with more confidence at work. Feeling out of depth was also significantly associated with not having a bleep-free teaching session (Mann-Whitney $U$ Test, $z=-4.069, P<0.001)$. Although those who had outpatient sessions, with a designated trainer undertaking teaching, were more confident with patient management, there was not a significant difference with those who did not have such supervision (MannWhitney $U$ Test, $z=-1.739, P=0.082$ ).

\section{Teaching and appraisal}

The majority of respondents, 64\%, had received formal training in medical examination of patients. Eightyfive per cent had been shown venous cannulation, 73\% urethral catheterisation, 5\% nasogastric tube 


\section{Table 4}

Band Allocated to Senior House Officer Posts

\begin{tabular}{|l|c|c|}
\hline Band of post & No. of SHOs & Percentage (\%) \\
\hline 3 & 94 & 42.0 \\
2A & 110 & 49.1 \\
2B & 15 & 6.7 \\
A & 4 & 1.8 \\
1B & 1 & 0.4 \\
\hline
\end{tabular}

placement, and 49\% arterial blood gas sampling. Almost all the senior house officers (94\%) have attended at least one of the following: hospital induction course (71\%), trauma course (34\%), postgraduate cardiopulmonary resuscitation course (49\%), or a dentist on the ward type course (41\%). Appraisal of trainees had not occurred for 29\% at any time during their post at the time of the questionnaire. Sixty-five per cent failed to have an appraisal around 1 week. This improved to $38 \%$ who failed to have an appraisal around 2 months.

\section{Hours of work}

SH0s were resident on-call (86.8\%), and 74\% were on either a 1 in 4 or 1 in 5 on call rota, Surprisingly, $42 \%$ of posts are band 3 (Table 4). The majority, $73 \%$ felt the band allocated was a fair reflection of the work intensity of their post. However, of those allocated Bands $2 \mathrm{a}, 2 \mathrm{~b}$ or less, associated with less remuneration, 58\% did not think the banding was a fair reflection of the work intensity of the post (Pearson $\chi^{2}=32.954, P<0.001$ ).

\section{Career plans}

Concerning career plans, 31\% did not know what their plans were. More UK graduates, 38.3\%, were unsure of career plans compared with $20 \%$ of nonUK graduates. Overall, 30\% had aspirations for a career in OMFS including medical school. Of non-UK graduates, $48.8 \%$ planned a career in OMFS including medical school compared with only $15.8 \%$ of UK graduates. The remaining 39\% of all SHOs had intentions to follow careers such as orthodontics, general dental practice, staff grade, surgical dentistry and restorative dentistry, for example.

\section{DISCUSSION}

\section{Response rate}

There is uncertainty surrounding the number of occupied SHO posts in OMFS in the United Kingdom at any period of time. If our estimates are correct then there was a good response rate approaching 76\%.

\section{Career progression}

It would appear the $57.2 \%$ who have been a SHO in OMFS for over 3 years are spending too long in the post. In practice only 2 years post qualification is necessary to satisfy the requirements for the MFDS. Our belief is that more than 3 years as a SHO in OMFS seems unnecessary. Of those who have already spent more than 3 years in the speciality,
20.2\% still did not know what their career plans were. Conversely, $40.3 \%$ were still planning to go to medical school and pursue a career in maxillofacial surgery. In agreement with Harris and Ferreira ${ }^{3}$ there seems to be bottleneck in the training. It is difficult to describe this as due to a lack of specialist registrar posts in OMFS as this is not the next step in their training, apart from possibly five who had both medical and dental degrees. Grant et al. in a survey of SHOs in medicine in 1989 found 25\% had been qualified for more than 4 years. ${ }^{15}$ We found $41.8 \%$ of the SHOs in our survey were qualified for more than 4 years. This demonstrates a definite lack of progression. For some this may be attributed to indecision. For the others, the reasons could be difficulty in obtaining places in medical school or training posts in dental specialities such as orthodontics or surgical dentistry.

\section{Non-UK qualified}

Non-UK graduate SHOs suffer more from prolonged time in SHO posts despite their possession of MFDS or FDS. The CMO's report recognises that the needs of overseas trainees are often not met. ${ }^{13}$ Many arrive in this country with different levels of training and objectives. There has been little attempt to assess their needs and provide appropriate training. One of the CMO's proposals are that the 'needs of non-UK qualified doctors are properly and fairly taken into account and that they have equal access to high quality training programmes.'

\section{Postgraduate qualifications}

SHOs in OMFS would seem to be better qualified than their counterparts in 1995. Only 12\% had FDS in $1995,{ }^{7}$ compared with 39\% having FDS or MFDS (which has now replaced the FDS) in this survey. This could be due the higher pass rates in the MFDS compared with the FDS exams.

\section{Training experience}

Concerning exposure to different aspects of OMFS, SHOs were more content about every aspect, when compared with the survey in $1995 .{ }^{7}$ Cleft lip and palate was the only area where the majority of senior house officers felt exposure was inadequate. However, exposure to cleft lip and palate cases is not felt to be a core requirement at this stage of training. The SHO post is seen to be part of general professional training in dentistry with preparation for the MFDS, and the restructuring of cleft lip and palate services in the UK means that there will be fewer centres for primary surgical repair.

\section{Weekly timetable}

Operating and ward work sessions are generally in line with the recommendations. Twenty-one per cent had three or more ward work sessions, while $10 \%$ had no sessions, in comparison with the recommended one session per week on average. One session of supervised general anaesthetic operating, and one session of supervised local anaesthetic operating are recommended. We grouped both local and general anaesthetic oper- 
ating sessions together. Nine per cent had one or less operating sessions, with $24 \%$ having five or more sessions. The number of out-patient sessions done by SHOs appears excessive, with $40 \%$ having four or more sessions per week, compared with the recommended one session per week on average.

\section{Supervision and teaching}

Unfortunately, 53\% of SHOs did not have a regular local anaesthetic minor oral surgery session with a designated trainer undertaking teaching. At least one supervised session and no more than one unsupervised session are recommended. In addition, 39\% of SHOs did not have any out-patient sessions with a designated trainer undertaking teaching. Again, they do not meet the requirements of at least one out-patient session per week with a trainer, and no more than one unsupervised session. One can envisage an increasing demand on trainers to provide supervision. It would not be unexpected if waiting lists increased as departments try to meet these recommendations, unless there was a reorganisation of service delivery.

Greater demands are being made to provide teaching. The equivalent of one bleep-free teaching session with an organised training curriculum including topics from the MFDS syllabus is recommended. Presently, only 39\% of respondents had bleep-free teaching sessions. Such absence of teaching and supervision could explain the lack of confidence some senior house officers have with patient management. Indeed, there was a significant association with lack of confidence and not having a bleep-free teaching session. Forty-eight per cent thought their undergraduate training had not prepared them for the job they were doing. This was particularly noted in those newly qualified with less time as senior house officers. Those who lacked supervision in out-patient clinics and had no bleep-free teaching sessions appeared more acutely aware of the perceived inadequacies of their undergraduate training.

Sixty-four per cent had received formal training in the medical examination of patients. However, since most SHOs in OMFS would be expected to clerk patients for theatre it is probably not acceptable that $36 \%$ of senior house officers are most likely doing something they have never been trained to do. Recent recommendations ${ }^{14}$ are that SHOs should only do this when it is established they are competent and their consultant has given permission.

SHOs in OMFS are expected to acquire skills in venepuncture, cannulation, arterial blood gas sampling and urinary catheterisation. ${ }^{14}$ Seventy-three per cent have been taught urethral catheterisation which is a vast improvement since 1995 when only 34\% had been taught this skill. ${ }^{7}$ Despite concerns regarding cardiopulmonary resuscitation (CPR) training of SHOs in OMFS by Cousins et al. ${ }^{16}$ in 1999 , we found only $49 \%$ had received postgraduate CPR training.

\section{Appraisal and induction}

Surprisingly, 29\% of SHOs had not attended an induction course, despite this being a basic training requirement. Twenty-nine per cent had never received any formal appraisal at any time during their post. It would seem that a significant number of educational supervisors are either unaware of their responsibilities, or are simply not supporting their trainees. Clark et al., (2002) recognised that educational supervisors had problems meeting the expectations of SHOs. They identified the challenge of time constraints and clinical and research responsibilities experienced by educational supervisors. ${ }^{17}$

\section{Hours of work}

There has been a big change in on-call commitments since $1995,{ }^{7}$ when $60 \%$ were on-call $1: 2$ or $1: 3$, compared with $5 \%$ in this survey. Of concern are that $42 \%$ of SHOs are in posts allocated band 3 due to work intensity. From December 2002, remuneration will be at $100 \%$ of basic pay. From August 2004, the European Working Time Directive (EWTD) will mean the maximum hours of duty for resident doctors will be 58 hours. ${ }^{18}$

\section{Conflict of commitments}

Significant pressures are mounting on hospitals to meet contractual obligations. Another increasing concern is commitments to improve SHO supervision and teaching. This will be another burden for the consultant to bear. It will be difficult to increase supervision and teaching without a reduction in clinical work. In addition, many SHOs are already working too many hours. Where will the additional staff come from to meet these clinical commitments? The expansion at consultant level in OMFS would appear to be delayed by the excessive length of training.

\section{Solutions?}

'A Health Service for all the talents: Developing the NHS workforce,' a consultation document on the review of workforce planning from the Department of Health comments on changes considered. It is suggested that 'some of our present SHO tasks would be done more appropriately by other medical staff, nurses, therapists, or the proposed 'physician's assistant'. The underlying aim should be to ensure that we do not employ more doctors as SHOs than are required for training purposes simply to meet service needs.'

The revolution in SHO training is likely to be far reaching as evidenced by government comments. 'In particular more of the service delivery out of hours as well as during the day will need to be provided by fully-trained staff. For instance we heard examples of consultants being resident on call over night and off duty the following day. Another approach, and one we believe requires serious consideration, would be to establish a new specialist grade which would be staffed by fully trained doctors and dentists who would work alongside consultants and be appropriately remunerated.1 
The time has come for change, which is likely to extend beyond the SHO grade. Our findings would support the case for change outlined in the CMOs report. ${ }^{13}$ We believe many of the deficiencies experienced by the SHOs in our survey can be attributed to poor job structure, poorly planned training, and no defined end point to SHO training. Again, our findings demonstrate 'inadequate supervision, assessment, appraisal and career advice.13

Reforms proposed are a two-year foundation programme, which replaces the current pre-registration year. A basic specialist training programme which would be time-capped would follow this. The final vision being a 'single training grade' which includes both these programmes, and higher specialist training. It is also proposed to shorten higher specialist training. Completion of training would means eligibility for appointment to a 'generalist' consultant post. There would be a period of more highly specialised training for those who wished to undertake it, and for which there was a service need. The non-consultant career grade is proposed to have its prestige enhanced with increased opportunity to enter (or re-enter) higher specialist training. We await the impact of changes in OMFS on both postgraduate dental and medical training.

\section{CONCLUSION}

Improvements have been made in the postgraduate qualifications, training exposure, and on-call frequency of SHOs in OMFS. However, too many SHOs are spending more time than necessary in this grade. This problem is most acute in non-UK graduates. Some SHOs still do not receive the expected basic training. There will need to be greater supervision and teaching of senior house officers undertaking local anaesthetic minor oral surgery and outpatient clinics. There are perceptions that dental undergraduate education does not prepare graduates adequately for senior house officer posts in oral and maxillofacial surgery. This problem is exacerbated by lack of teaching and supervision while in post. The role and responsibilities of those involved in educational supervision need to be emphasised. Greater access to career advice and counselling would be desirable.

The authors are grateful for the help and suggestions of $M r D G$ Smith, Postgraduate Dental Dean, Postgraduate Institute of Medicine and Dentistry, Newcastle

1. NHS Executive. A health service of all the talents: Developing the NHS workforce. London: Department of Health, 2000.

2. Grogono JL, Mumtaz FH, Booth MI. Service need versus training need. Ann R Coll Surg Engl (Suppl) 1993; 75: 101-103.

3. Dillner L. Senior house officers: the lost tribes. BrMed J 1993; 307 : 1549-1551.

4. Paice E, West G, Cooper R, Orton V, Scotland A. Senior House Officer Training: is it getting better? Br Med J 1997; 314: 719-720.

5. Baldwin P, Newton RW, Buckley G, Roberts MA, Dodd M. Senior house officers in medicine: postal survey of training and work experience. BrMed J 1997; 314: 740.

6a. Harris E, Ferreira P. Training senior house officers. Br Med J 1997; 314: 692.

6b. Cooke L, Hurlock S. Education and training in the senior house officer grade: results from a cohort study of United Kingdom medical graduates. Med Educ 1999: 33: 418-423.

7. Lyons AJ, Mills CC. Maxillofacial senior house officer posts: the trainee's perspective. Ann R Coll Surg Eng (suppl) 1995; 77: 242-245.

8. Working group on specialist medical training. Hospital doctors: training for the future. London: Department of Health, 1993.

9. NHS Executive. Junior Doctors: the new deal. London: Department of Health, 1991.

10. NHS Executive. Implementing the new deal. London: Department of Health, 1994

11. Paice $\mathrm{E}$, et al. Trainee satisfaction before and after the Calman reforms of specialist training : a questionnaire survey. Br Med J 2000; 320: 826-836.

12. General Medical Council. The Early Years - Recommendations on Senior House Officer Training. London, 1999.

13. Donaldson L. Unfinished Business - Proposals for reform of the senior house officer grade. London: Department of Health, 2002

14. Conference of Postgraduate Dental Deans and Directors, Faculty of Dental Surgery of the Royal College of Surgeons of England. A guide for skills required for house officers and senior house officers in the dental specialities in England and Wales. London, 2002.

15. Grant J, Marsden P, King RC. Senior house officers and their training. Personal characteristics and professional circumstances. BrMed J 1989; 299: 1263-1265.

16. Cousins GCS, Bassi GS, Lowry JC Cadiopulmonary resuscitation training of senior house officers in oral and maxillofacial surgery in the UK. Br J Oral Max Fac Surg 1999; $37: 1$.

17. Clark JD, Thomas M, Robertson L. A novel approach to promoting change in SHO training in a dental teaching hospital. Br Dent J 2002: 193: 167-171.

18. European Working Time Directive 93/104/EC 